\title{
Insensitivity of visual assessment of hippocampal atrophy in familial Alzheimer's disease
}

\author{
John Matthew Ringman • Whitney Pope • \\ Noriko Salamon
}

Received: 16 October 2009/Revised: 14 December 2009/Accepted: 16 December 2009/Published online: 3 January 2010

(C) The Author(s) 2010. This article is published with open access at Springerlink.com

\begin{abstract}
Medial temporal atrophy is a well-established marker for Alzheimer's disease (AD). However, due to normal variation in the size of medial temporal structures and variability in how radiologists interpret images, the use of clinical reads in establishing the presence of pathological atrophy is imprecise. A limitation of studies of magnetic resonance imaging (MRI) measures in $\mathrm{AD}$ is diagnostic uncertainty as it can be unknown if pre- or earlysymptomatic subjects go on to develop $\mathrm{AD}$ and most subjects do not undergo autopsy verification of the diagnosis. In persons with or at-risk for $\mathrm{AD}$ due to fullypenetrant autosomal dominant mutations in the PSENI and $A P P$ genes, the diagnosis or future development of AD can be predicted with essentially $100 \%$ accuracy. We used this predictability to assess the ability of radiologists to detect hippocampal atrophy (HA) in persons destined to develop AD. Coronal T1-weighted MRI scans of 39 persons demented from $(n=4)$ or at-risk for inheriting $(n=35)$ PSEN1 or APP mutations were independently assessed by two radiologists and the presence or absence of HA determined. Of the 39 subjects, 26 were FAD mutation carriers. Fifteen of 28 asymptomatic at-risk persons were FAD mutation carriers and four of these were rated as having atrophy for a sensitivity of $27 \%$ and a specificity of $85 \%$. Among seven mildly affected yet non-demented subjects, atrophy was detected in three and in the four
\end{abstract}

\author{
J. M. Ringman $(\varangle)$ \\ UCLA Department of Neurology, \\ Mary S. Easton Center for Alzheimer's Disease Research, \\ UCLA, 10911 Weyburn Ave., \#200, \\ Los Angeles, CA 90095-7226, USA \\ e-mail: jringman@mednet.ucla.edu \\ W. Pope $\cdot$ N. Salamon \\ UCLA Department of Radiology, UCLA, Los Angeles, USA
}

demented subjects HA was identified in two. Our results suggest that radiologists' ability to detect HA in persons in whom the diagnosis of incipient $\mathrm{AD}$ is certain is suboptimal and quantitative MRI techniques or other biological markers of the disease are needed.

Keywords Alzheimer's disease - Familial Alzheimer's disease - Magnetic resonance imaging - Hippocampus . Medial temporal lobe $\cdot$ Presenilin-1 · Amyloid precursor protein

Progressive cerebral atrophy, and medial temporal lobe atrophy in particular, has long been recognized as being characteristic of Alzheimer's disease (AD). The degree of such atrophy can be subtle or absent in early and particularly in presymptomatic disease but increases with disease severity. There is significant inter-individual variation in the volume of medial temporal lobe structures that increases with age and inter-observer reliability of judgment of medial temporal lobe size is sub-optimal [16]. It can therefore be challenging for a clinician to conclude whether the brain magnetic resonance imaging (MRI) scan of a given individual represents a normal degree of atrophy or if it is suggestive of a pathological process such as AD. A prior study showed that visual determination of medial temporal lobe atrophy in persons with mild cognitive impairment independently predicted progression to dementia but there was significant overlap between those who progressed and those who did not [7]. Quantitative volumetric techniques can be employed to differentiate patients with $\mathrm{AD}$ from controls based on the sizes of medial temporal lobe structures [6]. Such techniques, however, have not yet made their way into mainstream clinical neuroradiology and neurologists typically depend 
on their own readings or those of radiologists to estimate the degree to which a given brain size represents pathological atrophy.

One of the challenges to ascertaining how well the observed size of brain structures, as assessed visually by a radiologist, relates to clinical diagnosis in early or presymptomatic $\mathrm{AD}$ is difficulty in determining what the pathological diagnosis is in each case. For a presymptomatic population, subjects must be followed longitudinally for many years to determine who will and will not develop clinical symptoms. Even in established AD, the diagnostic accuracy can be as low as 75\% [8] and therefore, unless one obtains neuropathological verification of diagnosis, there is some uncertainty regarding the etiology underlying the clinical symptoms. In autosomal dominantly inherited $\mathrm{AD}$ of young onset (familial AD or FAD) due to mutations in the PSENI and APP genes, the ultimate development of $\mathrm{AD}$ can be predicted with essentially $100 \%$ certainty. Persons at-risk for the inheritance of these mutations therefore provide a model in which the sensitivity of radiological assessment of brain atrophy to the presence of incipient AD can be reliably tested.

In this study, two experienced neuroradiologists (authors N.S. and W.P.) rated the T1-weighted structural MRI scans of 39 demented $(n=4)$, mildly symptomatic $(n=7)$, or asymptomatic $(n=28)$ members of 13 families carrying known APP $(n=2)$ or PSENI $(n=11)$ mutations. Among families with PSEN1 mutations, one had the L235V [5], one the G206A [2], one an S212Y (unpublished, new variant), and eight had the A431E substitution. The A431E substitution in the PSEN1 gene represents a founder effect originating in Jalisco State in Mexico [12, 17]. The two families with APP mutations both had the V717I substitution that has been described in diverse populations worldwide [11]. Though the S212Y PSEN1 alteration has not previously been reported, there is substantial evidence for its pathogenicity. The single subject included in this study with it was clinically affected by dementia and her similarly affected brother (whose diagnosis of $\mathrm{AD}$ was verified on autopsy) was also demonstrated to carry it. Furthermore, an unaffected older sister was found not to have inherited it.

Clinical status was defined using the Clinical Dementia Rating (CDR score, $0=$ asymptomatic, $0.5=$ mildly symptomatic but not demented, $1=$ mildly, $2=$ moderately, and $3=$ severely demented) scale [10]. Subjects also underwent comprehensive neuropsychological testing and it was determined whether or not they met criteria for mild cognitive impairment [13] using previously published methods [15]. All demented and mildly symptomatic subjects were mutation carriers. Of the seven mildly symptomatic (CDR scores $=0.5$ ) subjects, six met neuropsychological criteria for mild cognitive impairment. Of the 28 asymptomatic (CDR scores $=0)$ subjects, 15 carried pathogenic APP or PSENI mutations with the remaining 13 subjects being non-mutation carrying family members. One mutation carrier with a CDR score of 0 met neuropsychological criteria for MCI. Chronological ages ranged from 19 to 59 . As age of onset can be consistent within families with these genes, a family-specific age relative to the age of typical dementia diagnosis ("relative age") was calculated for each subject. Relative ages varied ranged from 35 years prior to 18 years after the typical age for dementia diagnosis in their family.

All T1-weighted brain images were obtained in a uniform fashion on the same 1.5T Siemens Sonata scanner in the sagittal plane using a 3-D MP-RAGE sequence $(\mathrm{TR}=1,900 \mathrm{~ms}, \quad \mathrm{TE}=4.38 \mathrm{~ms}, \quad \mathrm{TI}=1,100 \mathrm{~ms}, \quad$ flip angle $15^{\circ}$, voxel size of $1 \times 1 \times 1 \mathrm{~mm}^{3}$ ). Two radiologists, blinded to all genetic and clinical information, independently rated atrophy of the right and left hippocampi on images reformatted in the coronal plane. Hippocampi were judged as either being normal (0, hippocampal height at the head to body level assessed as being greater than $10 \mathrm{~mm})$, or showing mild $(1,7-10 \mathrm{~mm})$, moderate $(2,5-7 \mathrm{~mm})$, or severe $(3,<5 \mathrm{~mm})$ atrophy. When asymmetry of the temporal horn was present, hippocampal height and configuration of the hippocampus (loss of indentation of the head of the hippocampus, flattening of the body of the hippocampus, etc.) were used to assess atrophy. This categorization was subsequently collapsed such that hippocampal atrophy was judged as being absent $(0)$ or present $(1,2,3=1)$. When the two radiologists were discrepant, they met and discussed the differences and made a consensus judgment as to whether or not atrophy was present.

Of the four demented subjects, two were rated as having no hippocampal atrophy (CDR scores of 2, see Fig. 1a). One subject with a CDR score of 3 was rated as having severe hippocampal atrophy bilaterally and one with a CDR score of 1 was rated as having mild hippocampal atrophy on the left side but not the right. Of the seven FAD mutation carriers with CDR scores of 0.5 , four were rated as having no atrophy, one as having bilateral hippocampal atrophy, and one each with right and left hippocampal atrophy only (all mild). Of the 15 asymptomatic FAD mutation carriers, 11 were rated as having no atrophy, three had bilateral, and one had unilateral atrophy (all mild). Among the 13 non-carriers, one was rated as having bilateral (Fig. 1b) and one unilateral mild hippocampal atrophy. Of note, these two subjects were not among the oldest subjects in the cohort being between 30 and 40 years of age (specific ages not given to protect confidentiality). In this study therefore, the sensitivity and specificity of hippocampal atrophy for predicting FAD mutation status in asymptomatic subjects was 27 and $85 \%$, respectively. 

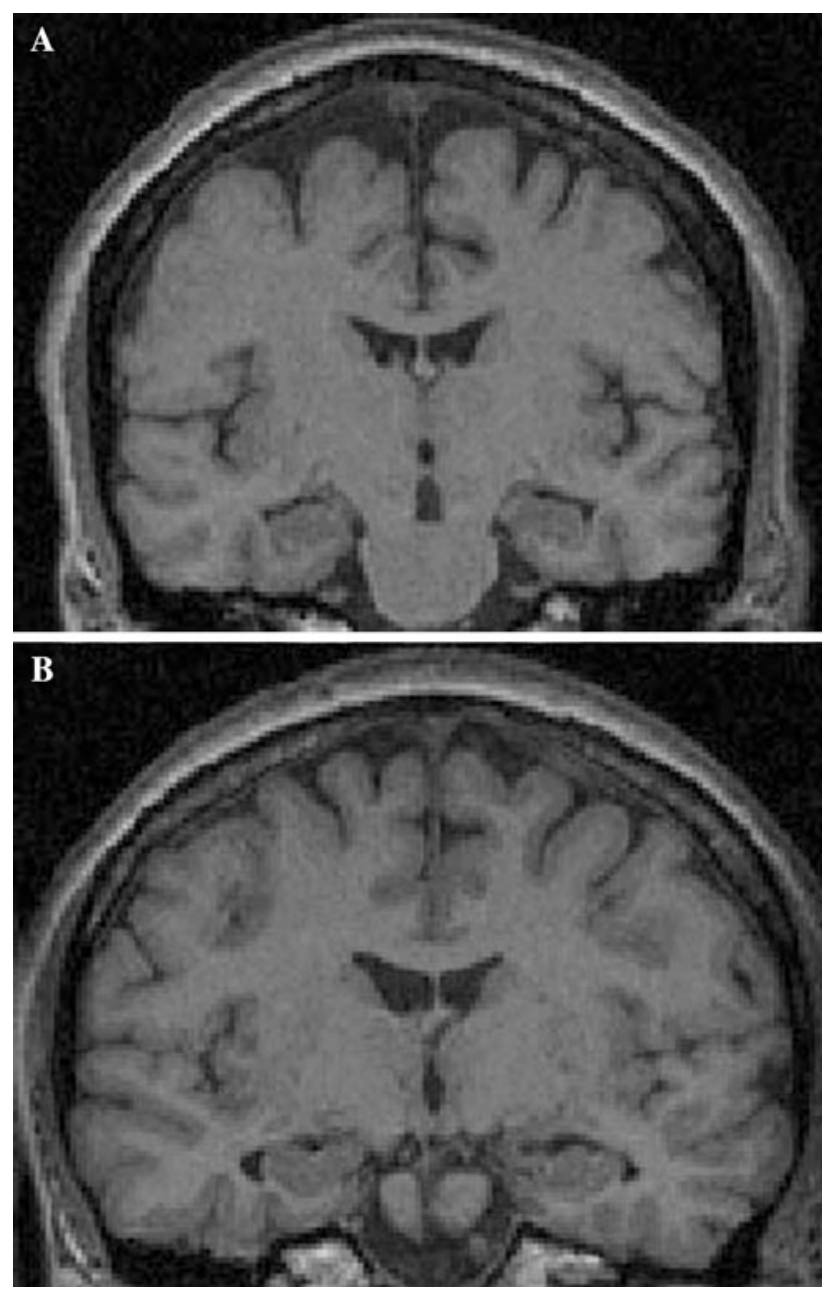

Fig. 1 a Coronal MP-RAGE MRI of a moderately demented subject $(\mathrm{CDR}=2)$ with FAD whose hippocampi were rated as having no atrophy by two experienced radiologists. b MRI of a non-mutation carrying person (age between 30 and 40 years) whose hippocampi were rated as mildly atrophic by both radiologists

Among mildly affected subjects (CDR scores of 0.5) sensitivity was $43 \%$ and in demented subjects it was $50 \%$.

In this population in which the future development of AD can be predicted with essentially $100 \%$ accuracy in presymptomatic persons, visual detection of hippocampal atrophy is an insensitive way of detecting early disease. This might be expected considering the young age of some subjects relative to the expected age of symptom onset. However, among the 22 non-demented (CDR scores $<1$ ) mutation carriers, the seven that were thought to have atrophy were between 1 and 18 years prior to the estimated age of disease diagnosis in their families. Among the four mutation carriers that were within 5 years of their estimated age of disease diagnosis, only one was thought to have HA. As visual interpretation of HA in mildly symptomatic mutation carriers $(\mathrm{CDR}$ scores $=0.5)$ had a sensitivity of only $43 \%$, neither clinical status nor age therefore predicted the presence of HA well.

A prior quantitative study of brain volumes in youngonset $\mathrm{AD}$ suggested that the pattern of gray matter loss can differ from $\mathrm{AD}$ of older onset with young onset patients having proportionally more atrophy of parietal and occipital cortex than of medial temporal lobe structures [4]. Another quantitative study, however, demonstrated that hippocampal atrophy does indeed occur in FAD and can be detectable 3-5.5 years prior to clinically diagnosable disease [14]. Our finding that visual assessment of hippocampal volume is insensitive to early atrophy in persons destined to develop FAD should therefore generalize, at least to some extent, to late onset AD.

Other biological markers such as FDG and PIB-PET scanning [3] and biochemical measurements in cerebrospinal fluid (CSF measurements of A $\beta 42$ and tau) [9] also have great promise in improving our ability to detect $\mathrm{AD}$ at early presymptomatic stages. Though not readily available to most clinicians, quantitative volumetric MRI measurements are more sensitive and predictive of subsequent clinical course in early AD [1] and therefore superior to visual inspection in this regard. Increased efforts are being made to increase the availability of such tools to the practitioner to augment their ability to diagnose $\mathrm{AD}$ early in the clinic.

Acknowledgments This project was supported by National Institute on Aging Public Health Service (PHS) K08 AG-22228, State of California Department of Health Services \#04-35522, and the Shirley and Jack Goldberg Trust. Further support for this study came from Alzheimer's Disease Research Center Grants P50 AG-16570, PHS R01 AG-21055 from the National Institute on Aging, General Clinical Research Centers Program M01-RR00865, and an Alzheimer's Disease Research Center of California grant.

Conflict of interest statement The authors have no conflict of interest to disclose.

Open Access This article is distributed under the terms of the Creative Commons Attribution Noncommercial License which permits any noncommercial use, distribution, and reproduction in any medium, provided the original author(s) and source are credited.

\section{References}

1. Apostolova LG, Dutton RA, Dinov ID, Hayashi KM, Toga AW, Cummings JL, Thompson PM (2006) Conversion of mild cognitive impairment to Alzheimer disease predicted by hippocampal atrophy maps. Arch Neurol 63:693-699

2. Athan ES, Williamson J, Ciappa A, Santana V, Romas SN, Lee JH, Rondon H, Lantigua RA, Medrano M, Torres M, Arawaka S, Rogaeva E, Song YQ, Sato C, Kawarai T, Fafel KC, Boss MA, Seltzer WK, Stern Y, St George-Hyslop P, Tycko B, Mayeux R (2001) A founder mutation in presenilin 1 causing early-onset 
Alzheimer disease in unrelated Caribbean Hispanic families. JAMA 286:2257-2263

3. Edison P, Archer HA, Hinz R, Hammers A, Pavese N, Tai YF, Hotton G, Cutler D, Fox N, Kennedy A, Rossor M, Brooks DJ (2007) Amyloid, hypometabolism, and cognition in Alzheimer disease: an [11C]PIB and [18F]FDG PET study. Neurology 68:501-508

4. Frisoni GB, Pievani M, Testa C, Sabattoli F, Bresciani L, Bonetti M, Beltramello A, Hayashi KM, Toga AW, Thompson PM (2007) The topography of grey matter involvement in early and late onset Alzheimer's disease. Brain 130:720-730

5. Janssen JC, Beck JA, Campbell TA, Dickinson A, Fox NC, Harvey RJ, Houlden H, Rossor MN, Collinge J (2003) Early onset familial Alzheimer's disease: mutation frequency in 31 families. Neurology 60:235-239

6. Kesslak JP, Nalcioglu O, Cotman CW (1991) Quantification of magnetic resonance scans for hippocampal and parahippocampal atrophy in Alzheimer's disease. Neurology 41:51-54

7. Korf ES, Wahlund LO, Visser PJ, Scheltens P (2004) Medial temporal lobe atrophy on MRI predicts dementia in patients with mild cognitive impairment. Neurology 63:94-100

8. Lim A, Tsuang D, Kukull W, Nochlin D, Leverenz J, McCormick W, Bowen J, Teri L, Thompson J, Peskind ER, Raskind M, Larson EB (1999) Clinico-neuropathological correlation of Alzheimer's disease in a community-based case series. J Am Geriatr Soc 47:564-569

9. Mattsson N, Zetterberg H, Hansson O, Andreasen N, Parnetti L, Jonsson M, Herukka SK, van der Flier WM, Blankenstein MA, Ewers M, Rich K, Kaiser E, Verbeek M, Tsolaki M, Mulugeta E, Rosen E, Aarsland D, Visser PJ, Schroder J, Marcusson J, de Leon M, Hampel H, Scheltens P, Pirttila T, Wallin A, Jonhagen ME, Minthon L, Winblad B, Blennow K (2009) CSF biomarkers and incipient Alzheimer disease in patients with mild cognitive impairment. JAMA 302:385-393
10. Morris JC (1997) Clinical dementia rating: a reliable and valid diagnostic and staging measure for dementia of the Alzheimer type. Int Psychogeriatr 9 Suppl 1:173-176 (discussion 177-178)

11. Mullan M, Tsuji S, Miki T, Katsuya T, Naruse S, Kaneko K, Shimizu T, Kojima T, Nakano I, Ogihara T et al (1993) Clinical comparison of Alzheimer's disease in pedigrees with the codon $717 \mathrm{Val} \rightarrow$ Ile mutation in the amyloid precursor protein gene. Neurobiol Aging 14:407-419

12. Murrell J, Ghetti B, Cochran E, Macias-Islas MA, Medina L, Varpetian A, Cummings JL, Mendez MF, Kawas C, Chui H, Ringman JM (2006) The A431E mutation in PSEN1 causing familial Alzheimer's disease originating in Jalisco State, Mexico: an additional fifteen families. Neurogenetics 7:277-279

13. Petersen RC (2004) Mild cognitive impairment as a diagnostic entity. J Intern Med 256:183-194

14. Ridha BH, Barnes J, Bartlett JW, Godbolt A, Pepple T, Rossor MN, Fox NC (2006) Tracking atrophy progression in familial Alzheimer's disease: a serial MRI study. Lancet Neurol 5:828834

15. Ringman JM, Medina LD, Rodriguez-Agudelo Y, Chavez M, Lu P, Cummings JL (2009) Current concepts of mild cognitive impairment and their applicability to persons at-risk for familial Alzheimer's disease. Curr Alzheimer Res 6:341-346

16. Scheltens P, Launer LJ, Barkhof F, Weinstein HC, van Gool WA (1995) Visual assessment of medial temporal lobe atrophy on magnetic resonance imaging: interobserver reliability. J Neurol 242:557-560

17. Yescas P, Huertas-Vazquez A, Villarreal-Molina MT, Rasmussen A, Tusie-Luna MT, Lopez M, Canizales-Quinteros S, Alonso ME (2006) Founder effect for the Ala431Glu mutation of the presenilin 1 gene causing early-onset Alzheimer's disease in Mexican families. Neurogenetics 7:195-200 